\title{
STRUCTURAL EFFECTS OF THE AU(I) DRUG AURANOFIN ON CELL MEMBRANES AND MOLECULAR MODELS
}

\author{
MARIO SUWALSKYa*, RAQUEL GONZÁLEZ ${ }^{a}$, FERNANDO VILLENA ${ }^{b}$, SILVIA BOLOGNIN ${ }^{c}$ \\ ${ }^{a}$ Faculty of Chemcal Sciences, University of Concepción, Concepción, Chile \\ ${ }^{b}$ Faculty of Biological Sciences, University of Concepción, Concepción, Chile \\ 'University of Verona, Verona, Italy \\ (Received: July 1, 2013 - Accepted: September 24, 2013)
}

\begin{abstract}
Auranofin is a gold compound that is widely used for the treatment of rheumatoid arthritis. It is a monomeric linear complex with triethylphosphine and thiolate moieties bounded to an $\mathrm{Au}(\mathrm{I})$ center. Gold compounds are well known for their neurological and nephrotoxic implications. However, haematological toxicity is one of the most serious toxic and less studied effects. The lack of information on these aspects of auranofin prompted us to study the structural effects induced on cell membranes, particularly that of human erythrocytes. Auranofin was incubated with intact erythrocytes and molecular models of the erythrocyte membrane. The latter consisted of multibilayers of dimyristoylphosphatidylcholine (DMPC) and dimyristoylphosphatidylethanolamine (DMPE), phospholipids classes located in the outer and inner monolayers of the human erythrocyte membrane, respectively. This report presents evidence in order that auranofin interacts with red cell membranes as follows: a) in scanning electron microscopy studies on human erythrocytes it was observed that auranofin induced shape changes; b) X-ray diffraction studies showed that auranofin induced increasing structural perturbation to DMPC and to a lower extent to DMPE bilayers. Additional

experiments were performed in human neuroblastoma cells SH-SY5Y. A statistically significant decrease of cell viability was observed.
\end{abstract}

Keywords: Gold; $\mathrm{Au}(\mathrm{I})$; phospholipid bilayer; erythrocyte membrane; neuroblastoma cells.

Abbreviations: SEM, scanning electron microscopy; MTT, dimyristoylphosphatidylcholine; DMPE, dimyristoylphosphatidylethanolamine.

3-(4,5-dimethylthiazol-2-yl)-2,5-diphenyltetrazolium bromide; DMPC,

(a) 
min at $30^{\circ} \mathrm{C}$ and $60^{\circ} \mathrm{C}$ with DMPC and DMPE, respectively. Samples were then transferred to $1.5 \mathrm{~mm}$ dia. special glass capillaries (Technik \& Konstruktion, Berlin, Germany) and X-ray diffracted. Specimen-to-film distances were 8 and $14 \mathrm{~cm}$, standardized by sprinkling calcite powder on the capillary surface. $\mathrm{Ni}-$ filtered $\mathrm{CuK} \alpha$ radiation from a Bruker Kristalloflex 760 (Karlsruhe, Germany) $\mathrm{X}$-ray generator was used. The relative reflection intensities were obtained in an MBraun PSD-50M linear position-sensitive detector system (Garching, Germany); no correction factors were applied. The experiments were performed at $18 \pm 1{ }^{\circ} \mathrm{C}$, which is below the main phase transition temperature of both DMPC $\left(24.3^{\circ} \mathrm{C}\right)$ and DMPE $\left(50.2^{\circ} \mathrm{C}\right)^{15,16}$. Higher temperatures would have induced transitions to more fluid phases making the detection of structural changes harder. Each experiment was performed in triplicate and in case of doubts additional experiments were carried out.

\subsection{Scanning electron microscope (SEM) studies of human} erythrocytes.

Blood was obtained from healthy donors not receiving any pharmacological treatment. Blood samples $(0.1 \mathrm{ml})$ were obtained by puncture of the ear lobule and received in an Eppendorf tube containing $50 \mu 1$ of heparin $(5000 \mathrm{UI} / \mathrm{ml})$ in $0.9 \mathrm{ml}$ of saline solution $(\mathrm{NaCl} 0.9 \%, \mathrm{pH}=7.4)$. The samples were centrifuged $(1000 \mathrm{rpm} \times 10 \mathrm{~min})$ and the supernatant was discarded and replaced by the same volume of saline solution; the whole process was repeated three times. The sedimentary red blood cells were suspended in $0.9 \mathrm{ml}$ of saline solution and fractions of this stock of red blood cells suspension (RBCS) were placed in Eppendorf tubes to prepare (a) the control, by mixing $0.1 \mathrm{ml}$ of saline solution plus $0.1 \mathrm{ml} \mathrm{RBCS}$, and (b) auranofin in a range of concentrations by mixing 0.1 $\mathrm{ml}$ of RBCS with $0.1 \mathrm{ml}$ of adequate auronofin stock solution concentrations in saline. All samples were then incubated at $37^{\circ} \mathrm{C}$ for $1 \mathrm{~h}$. After the incubation, samples were centrifuged $(1000 \mathrm{rpm} \times 10 \mathrm{~min})$ and the supernatant was discarded. Afterwards, they were fixed overnight at $4{ }^{\circ} \mathrm{C}$ by adding $0.5 \mathrm{ml}$ of $2.5 \%$ glutaraldehyde in distilled water, reaching a final fixation concentration of about $2.4 \%$. Fixed samples were washed three times by centrifugation with distilled water, placed on $\mathrm{Al}$ glass cover stubs, air dried at $37^{\circ} \mathrm{C}$ for $30 \mathrm{~min}$, and gold-coated in a sputter device (Edwards S150, Sussex, England). Resulting specimens were examined in a Jeol SEM (JSM 6380 LB, Japan).

\subsection{Viability studies on human neuroblastoma cells.}

SH-SY5Y human neuroblastoma cells were purchased from ECACC (European Collection of Cell Culture, Salisbury, UK). SH-SY5Y were cultured in DMEM/ F12 (Gibco, Carlsbad, CA USA) medium containing $15 \%(\mathrm{v} / \mathrm{v})$ fetal bovine serum (FBS, Sigma Aldrich, St. Louis, MO), 100 units/ml penicillin (Gibco, Carlsbad, CA USA) and streptomycin $(100 \mu \mathrm{g} /$ $\mathrm{ml}$; Gibco, Carlsbad, CA USA), at $37{ }^{\circ} \mathrm{C}$ with $5 \% \mathrm{CO}_{2}$ in a humidified atmosphere (90\% humidity). The medium was replaced every 2 days. $0.25 \%$ Trypsin-EDTA solution and phosphate buffered saline (PBS) were obtained from Sigma Aldrich (St. Louis, MO). Cell viability was assessed by medans of the 3-(4,5-dimethylthiazol-2-yl)-2,5-diphenyltetrazolium bromide (MTT) reduction assay (Sigma Aldrich St. Louis, MO). Briefly, SHSY5Y cells were seeded into 24 -well plates (at a density of $10 \times 10^{4}$ cells per well, in $1.5 \mathrm{ml}$ medium). $2 \%$ FBS medium containing auranofin at a concentration range from $1 \mathrm{nM}$ to $1 \mu \mathrm{M}$ was added to the cells for $1,6,24$ and $48 \mathrm{~h}$. MTT $(5 \mathrm{mg} / \mathrm{ml})$ was added to each well and incubated in the dark at $37^{\circ} \mathrm{C}$ for $3 \mathrm{~h}$ followed by cells lysis and spectrophotometric measurement at $550 \mathrm{~nm}$ (Microplate SPECTRAmax ${ }^{R}$ at 550$)$. The MTT solution was carefully decanted off, and formazan was extracted from the cells with $1 \mathrm{ml}$ of acidic isopropanol $(0.04$ $\mathrm{M} \mathrm{HCl}$ in absolute isopropanol) in each well ${ }^{17}$. Colour was measured with a 96-well ELISA plate reader. All MTT assays were performed in three times in triplicate. All readings were compared with the control, which represented $100 \%$ viability. Data regarding MTT assay were performed using T-test, Primer software and reported as highly statistically significant if $\mathrm{P}<0.01$ and statistically significant if $\mathrm{P}<0.05$. Results are presented as mean \pm standard deviation.

\section{RESULTS}

3.1 X-ray diffraction studies on DMPC and DMPE multilayers.

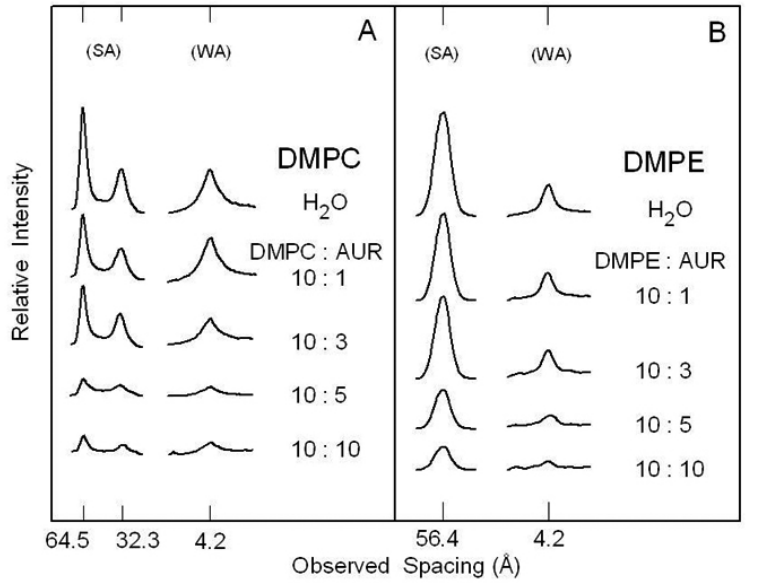

Figure 2. X-ray diffraction patterns of DMPC (A) and DMPE (B) in water and aqueous suspensions of auronafin; (SA) small-angle and (WA) wide-angle reflections.

Figure 2A exhibits the results obtained by incubating DMPC with water and auranofin. As expected, water altered the DMPC structure: its bilayer repeat (bilayer width plus the width of the water layer between bilayers) increased from about $55 \AA$ in its dry crystalline form to $64.5 \AA$ when immersed in water (gel phase) and its small-angle reflections (SA), which correspond to the bilayer repeat, were reduced to only the first two orders of the bilayer width $^{15}$. On the other hand, only one strong reflection of $4.2 \AA$ showed up in the wide-angle region (WA), which corresponds to the distance between the neighboring planes in the nearly hexagonal packing of the fully extended acyl chains. These results were indicative of the changes in layer and chain packing structure reached by DMPC bilayers. Figure 2A also discloses that after exposure to 10:1 and higher auranofin ratios there was a weakening of the small- and wide-angle lipid reflection intensities (indicated as (SA) and (WA) in the Figure, respectively); From these results, it can be concluded that auranofin produced a significant structural perturbation of DMPC bilayers. Figure $2 \mathrm{~B}$ shows the results of the X-ray diffraction analysis of DMPE bilayers incubated with water and auranofin. As reported elsewhere, water did not significantly affect the bilayer structure of DMPE ${ }^{15}$. Figure $2 \mathrm{~B}$ also shows that auroanofin caused a weakening in DMPE reflection intensities but at higher concentrations than those observed with DMPC.

3.2 Scanning electron microscope (SEM) studies of human erythrocytes.
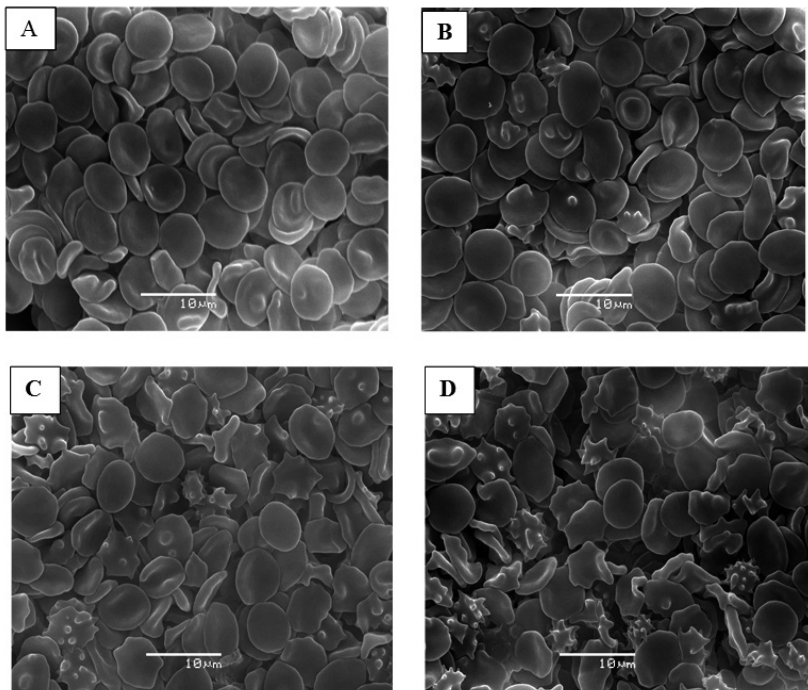

Fgure 3. Effects of auranofin on the morphology of human erythrocytes: (A) SEM images of untreated erythrocytes; (B) incubated with $0.1 \mathrm{mM}$, (C) 1 $\mathrm{mM}$, and (D) $3.0 \mathrm{mM}$ auranofin. 
SEM examinations of human erythrocytes incubated with auranofin indicated that different changes to the normal biconcave morphology of the red blood cells (Figure 3) were induced . Figure 3B shows that when incubated with $0.1 \mathrm{mM}$ auranofin about a third of the cells are echinocytes (a spiny configuration with blebs in the cell surface), while some elliptocytes are also present, with $1 \mathrm{mM}$ almost half of the cells are echnocytes (Figure 3C), and with $3 \mathrm{mM}$ auranofin $80 \%$ of the cells are echinocytes (Figure 3D).

3.3 Viability studies on human neuroblastoma cells.
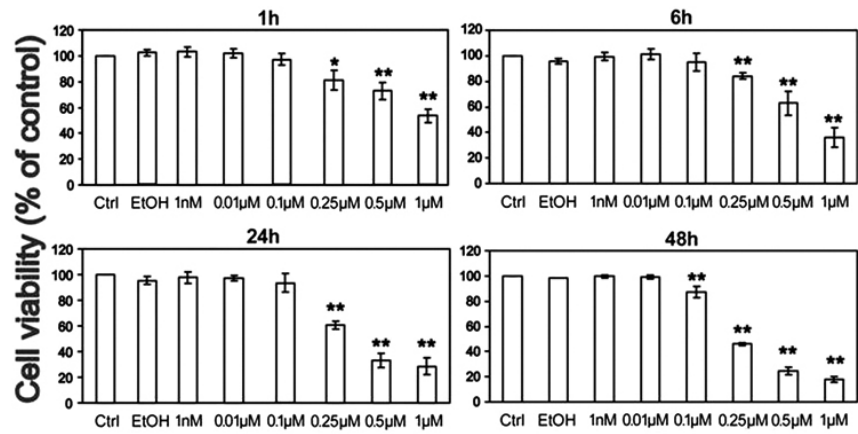

Figure 4. Redox activity in SH-SY5Y neuroblastoma cells after treatment with auranofin. Neuroblastoma redox activity was measured by MTT assay. The data represented are mean $\pm \mathrm{SD}$ of two individual experiments, each done

in duplicate. ${ }^{*} \mathrm{P}<0.05, * * \mathrm{P}<0.01$ vs. control.

The effect of auranofin on human SH-SY5Y neuroblastoma cells were tested at a concentration range from $1 \mathrm{nM}$ to $1 \mu \mathrm{M}$. Cells were incubated for 1, 6, 24 and $48 \mathrm{~h}$. As shown in Figure 4, the number of viable cells decreased highly significantly after $1 \mathrm{~h}$ with 0.5 and $1 \mu \mathrm{M}$ treatments. The effect also persisted at 6,24 and $48 \mathrm{~h}$, and was not recovered. $0.25 \mu \mathrm{M}$ treatment appeared to be only partially toxic after $1 \mathrm{~h}$, but it became toxic after 6 and more markedly after $24 \mathrm{~h}$, being the toxicity comparable to 0.5 and $1 \mu \mathrm{M}$ treatments.

\section{DISCUSSION}

Gold compounds are well known for their toxicological aspects, mainly neurological and nephrotoxical implications. However, haematological toxicity is one of the most serious toxic and less studied effects. One of the few reports indicates a strong binding of gold to the erythrocyte membrane via thiol pairs in patients receiving sodium aurothiomalate (Myocrisin) ${ }^{18}$; preliminary studies of rheumatoid arthritis patients indicated very different gold uptake into red blood cells depending on the particular patient ${ }^{19} ; \mathrm{AuCl}$ and aurothiomalate incubated with human erythrocytes triggered exposure of phosphatidylserine at the erythrocyte surface stimulating cell shrinkage and death ${ }^{20}$, and intact erythrocytes incubated with tetrachloroauric acid and $\mathrm{AuCl}_{3}$ changed their morphology ${ }^{13,14}$. Our X-ray diffraction analysis showed that auranofin induced structural perturbations of the polar head group and to the hydrophobic acyl regions of DMPC and DMPE, being these effects somewhat stronger in DMPC. Chemically, these two lipids only differ in their terminal amino groups, being these $\mathrm{N}\left(\mathrm{CH}_{3}\right)_{3}$ in DMPC and $\mathrm{NH}_{3}$ in DMPE. Moreover, both molecular conformations are very similar in their dry crystalline phases: their acyl chains are mostly parallel and extended with the polar groups lying perpendicularly to them; however, DMPE molecules pack tighter than those of DMPC. This effect, due to the DMPE smaller polar group and higher effective charge, produces a very stable multilayer system held by electrostatic interactions and hydrogen bonds ${ }^{15}$. On the other hand, the gradual hydration of DMPC bilayers leads to water filling the highly polar interbilayer spaces. Consequently, there is an increase in its bilayer repeat from $54.5 \AA$ when dry (crystalline phase) up to $64.5 \AA$ when fully hydrated at a temperature lower than that of its main transition (gel phase). This condition promoted the incorporation of auranofin molecules into the DMPC interbilayer space and the ensuing molecular perturbation of the phospholipid bilayer structure.

SEM examination of intact human red cells showed that $0.1 \mathrm{mM}$ and higher auranofin concentrations induced a change of their normal biconcave shape. According to the bilayer-couple hypothesis ${ }^{21,22}$, shape changes are induced in red cells due to the insertion of foreign species in either the outer or the inner monolayer of the erythrocyte membrane. Thus, spiculated shapes (echinocytes) are observed in the first case while cup shapes (stomatocytes) are produced in the second due to the differential expansion of the corresponding monolayer. The extent of the interaction of auranofin with DMPC was higher than that with DMPE, the lipid classes preferentially located in the outer and inner monolayers of the erythrocyte membrane, respectively. Thus, it was not surprising to observe the expected echinocytes. The experimental findings are certainly of interest as they indicate that auranofin affects the human erythrocyte morphology. It must be considered that alteration of the normal biconcave shape of red blood cells increases their resistance to entry into capillaries, which could contribute to decreased blood flow, loss of oxygen, and tissue damage through microvascular occlusion ${ }^{23,24}$.

The scarce information on gold toxicity, especially in the brain, prompted us to study its potential effect on neuroblastoma cell culture. We chose SHSY5Y line because it is widely used in the neuroscience research and it can be considered a good indicator for viability experiments. As gold is a promising bio-conjugated in medicine for cancer treatment its toxicity appeared to be crucial. In our experimental model, $1 \mu \mathrm{M}$ auranofin determined a significant reduction of cell viability after different times of incubation.

It has been reported that after 6-12 weeks of therapeutic treatment with oral auranofin, the blood concentration of gold reaches $0.9 \mathrm{mg} / \mathrm{L}$ (equivalent to $5 \mu \mathrm{M})^{25}$. Although it is known that most of the gold binds to human serum albumin and is taken up by the red blood cells ${ }^{26}$, it should be understood that therapeutic levels are the steady-state concentrations necessary to be reached for the drug to exert a significant clinical benefit. On the other hand, neurotoxicity following a very high dose of oral auranofin $(5.4 \mathrm{mg} / \mathrm{kg})$ gold concentration can reach a concentration calculated to be equivalent to 0.4 $\mathrm{mM}^{27}$. Our experimental results indicated that $1 \mu \mathrm{M}$ auranofin affected the viability of neuroblastoma cells and $0.1 \mathrm{mM}$ auranofin induced significant morphological changes to human erythrocytes.

\section{CONCLUSIONS}

Our experimental results indicate that auranofin interacts with phospholipid bilayers perturbing their molecular structures. Permeability and functions of ion channels, receptors and enzymes immersed in the membrane lipid moiety might also be affected. These findings may provide a new insight into the possible mechanism for the toxicity of gold at the cell membrane level.

\section{ACKNOWLEDGEMENTS}

This work was supported by a grant from FONDECYT (1130043).

\section{REFERENCES}

1. J. Emsly, The elements (II edition). Clarendon Press, Oxford, 1980; p. 81.

2. D.G. Richards, D.L. McLillin, E.A. Mein, C.D. Nelson, Int. J. Neurosci 112, 31, (2002)

3. L. Messori, G. Marcon, Metal Ions Biol. Syst. 41, 279 (2004).

4. J.R. Roberts, C.F. Shaw III, Biochem. Pharmacol. 55, 1291, (1998).

5. G. Danscher, Histochem. Cell. Biol. 117, 447, (2002).

6. J.D. Herlinger, C. Alsen, R. Beress, U. Hecker, W. Weiker, J. Rheumatol. 9, 81, (1982).

7. Martindale (J.E.F. Reynolds. Ed.), The Pharmaceutical Press, London, p.7, 1993,

8. C-M. Chen, R. Wai-Yin Sun, W-Y. Yu, C-B. Ko, N. Zhu, H. Sun, Chem. Comm. 1718, (2003).

9. D.Fan, C-T. Yang, J.D. Ranford, J. J. Vittal, P.F. Lee, Dalton Trans. 17, 3376 (2003).

10. J.M. Boon, B.D. Smith, Med. Res. Rev. 22, 251, (2002).

11. P.F. Devaux, A. Zachowsky, Chem. Phys. Lipids 73, 107, (1994).

12. M. Suwalsky, P. Zambenedetti, E. Carpené, M. IbnLkayat, W. Wittkowski, L. Messori, P. Zatta, J. Inorg. Biochem. 98, 2080, (2004).

13. M. Suwalsky. R. González, F. Villena, L.A. Aguilar, C.P. Sotomayor, S. Bolognin. P. Zatta, Coord. Chem. Rev. 253, 1590, (2009).

14 M. Suwalsky, R. González, F. Villena, L.F. Aguilar, C.P. Sotomayor, S. Bolognin, P. Zatta, Biochem. Biophys. Res. Commun. 397 (2010), 226.

15. M. Suwalsky in Phospholipid Bilayers, in Polymeric Materials Encyclopedia, J.C. Salamone ed. CRC Press, Boca Raton, 1996; pp. 50735078

16. R. Koynova, M. Caffrey, Biochim. Biophys. Acta 1376, 91, (1998). 
17. M.S. Shearman, S.R. Hawtin, V.J. Tailor, J. Neurochem. 65, 218, (1995).

18. J.M. Campbell, J. Reglinski, W.E. Smith, D. Porter, R.D. Sturrock, Ann. Rheum. Dis. 51, 969, (1992).

19. Y. Zhang, E.V. Hess, K.G. Pryhuber, J.G. Dorsey, K. Tepperman, R.C. Elder, Inorg. Chim. Acta 229, 271, (1995).

20. M. Sopjani, M. Föller, F. Lang, Toxicology 244, 271, (2008).

21. M.P. Sheetz, S.J. Singer, P. Natl. Acad. Sci. USA 71, 4457, (1974).

22. G. Lim, M. Wortis, R. Mukhopadhyay, P. Natl. Acad. Sci. USA 99, 16766 , (2002).
23. S.L. Winski, D.E. Carter, J. Toxicol. Env. Health A, 53, 345, (1998).

24. S. Svetina, D. Kuzman, R.E. Waugh, P. Zibert, B. Zeks, Bioelectrochemist. 62, 107, (2004).

25. D. Lewis, H.A. Capell, C.J. M cNeil, M.S. Iqbal, D.H. Brown, W.E. Smith, Ann. Rheum. Dis. 42, 566 (1983).

26. A. Albert, C. Brauckmann, F. Blaske, M. Sperling, C. Engelhard, U. Karst, J. Anal. At. Spectrom. 27, 975 (2012).

27. P. Gambari, P. Ostuni, P. Lazzarn, B. Tavolato, S. Todesco, Arthritis Rheum. 27, 1316 (1984). 